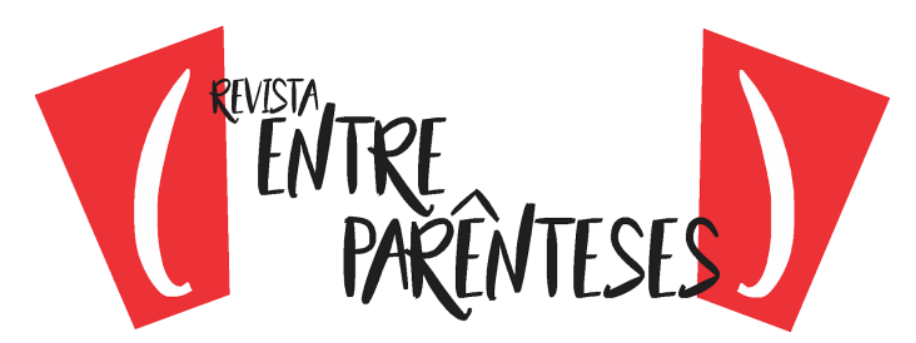

\title{
LÍNGUA E LITERATURA: DISPUTAS DISCURSIVAS NOS CONTEXTOS DE FORMAÇÃO DOCENTE
}

\author{
https://doi.org/10.32988/rep.v1n9.1125
}

\author{
Elíria Quaresma Fugazza1 \\ Universidade Federal de Alfenas \\ (eliriaq@hotmail.com)
}

\begin{abstract}
Resumo: Com base em uma revisão bibliográfica e teórica advinda de estudos em Análise do Discurso (AUTHIER-REVUZ, 2004; MAINGUENEAU, 2013; SERRANI, 1997), teorias do discurso (BAKHTIN, 2006; FOUCAULT, 2014a) e da teoria dos campos de Bourdieu (1976, 2002), discutimos, neste trabalho, o caráter dialógico e heterogêneo da língua e do discurso, bem como a natureza fragmentada e contraditória dos sujeitos e sentidos. Além disso, almejamos problematizar os movimentos de aproximação e/ou cisão entre as formações discursivas e os campos epistemológicos relacionados aos estudos linguísticos e literários, a partir de Brait (2000) e Fiorin (2008), considerando a história dos processos de separação de ambos os saberes. Concluímos, nesse sentido, apontando tensões e imbricações que correspondem a um movimento simultâneo de reprodução da cisão língua vs. literatura e de diálogo entre esses campos nos contextos de formação docente em língua estrangeira.
\end{abstract}

Palavras-chave: Relação língua/literatura; Formação docente; Formações discursivas; Campos epistemológicos; Análise do Discurso.

\section{LANGUAGE AND LITERATURE: DISCURSIVE DISPUTES IN THE TEACHING TRAINING CONTEXTS}

Abstract: Based on a bibliographic and theoretical review from studies in Discourse Analysis (AUTHIER-REVUZ, 2004; MAINGUENEAU, 2013; SERRANI, 1997), discourse theories (BAKHTIN, 2006; FOUCAULT, 2014a) and Bourdieu's theory of fields $(1976,2002)$, we discuss, in this paper, about the heterogeneous and dialogical character of language and discourse, such as the fragmented and contradictory nature of subjects and meanings. Besides that, we aim to discuss about the movements of approximation and/or dichotomy between the discursive formations and the epistemological fields related to linguistic and literary studies, based on Brait (2000) and Fiorin (2008), considering the history of processes of separation of both knowledges. We conclude, in that sense, by pointing out tensions and interdependences that correspond to a simultaneous movement of reproduction of the dichotomy language vs. literature and dialogue between these fields in contexts of teacher's training in a foreign language.

Keywords: Language/ literature relationship; Teacher's training; Discursive formations; Epistemological fields; Discourse Analysis.

\section{LENGUA Y LITERATURA: DISPUTAS DISCURSIVAS EN EL CONTEXTO DE FORMACIÓN DOCENTE}

Resumen: Con base en una revisión bibliográfica y teórica de los estudios en Análisis del Discurso (AUTHIER-REVUZ, 2004; MAINGUENEAU, 2013; SERRANI, 1997), teorías del discurso (BAKHTIN, 2006; FOUCAULT, 2014a) y de la teoría de los campos de Bourdieu (1976, 2002), discutimos, en este trabajo, el carácter dialógico y heterogéneo de la lengua y del discurso, así como la naturaleza

${ }^{1}$ Doutoranda do Programa de Pós-Graduação em Letras Neolatinas da Universidade Federal do Rio de Janeiro (UFRJ). Professora assistente do Departamento de Letras da Universidade Federal de Alfenas. 


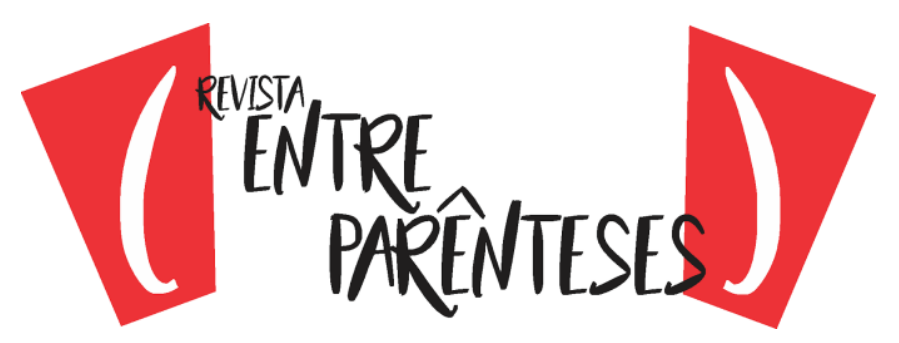

fragmentada y contradictoria de los sujetos y sentidos. Además, objetivamos problematizar los movimientos de acercamiento y/o cisión entre las formaciones discursivas y los campos epistemológicos relacionados a los estudios lingüísticos y literarios, a partir de Brait (2000) y Fiorin (2008), considerando la historia de los procesos de separación de ambos saberes. Concluimos, en ese sentido, apuntando tensiones e imbricaciones que corresponden a un movimiento simultáneo de reproducción de la cisión lengua vs. literatura y de diálogo entre esos campos en los contextos de formación docente en lengua extranjera.

Palabras-clave: Relación lengua/literatura; Formación docente; Formaciones discursivas; Campos epistemológicos; Análisis del Discurso.

\section{DIALOGISMO E FORMAÇÃO DOCENTE}

Neste artigo, discutimos o caráter heterogêneo e dialógico do discurso e da enunciação, buscando, assim, problematizar os movimentos de separação e/ou cisão entre os campos epistemológicos ligados aos estudos linguístico e literário no âmbito da formação de professores de línguas estrangeiras.

De acordo com Bakhtin (2006, p. 130), "a língua constitui um processo de evolução ininterrupto, que se realiza através da interação verbal social dos locutores". O autor ainda afirma que o espaço semiótico e o "papel contínuo da comunicação social como fator condicionante não aparecem em nenhum lugar de maneira mais clara e completa do que na linguagem" (idem, p. 34) e considera, dentro do enfoque discursivo, a palavra enquanto signo social que acompanha toda criação ideológica.

Authier-Revuz (2004) define os enunciados como acontecimentos concretos e únicos produzidos na interação da língua e portadores de um acento apreciativo. Todos os enunciados, portanto, carregam consigo um julgamento de valor, o que se relaciona diretamente à não neutralidade do discurso e à possibilidade de um enunciado responder aos outros enunciados, seja corroborando-os ou opondo-se a eles.

De modo semelhante, Maingueneau (2013, p. 60) afirma que toda enunciação é perpassada por uma interatividade constitutiva, ou seja, é dialógica, pois "é uma troca, explícita ou implícita, com outros enunciadores, virtuais ou reais, e supõe sempre a presença de uma outra instância de enunciação à qual se dirige o enunciador e com relação à qual constrói seu próprio discurso". 


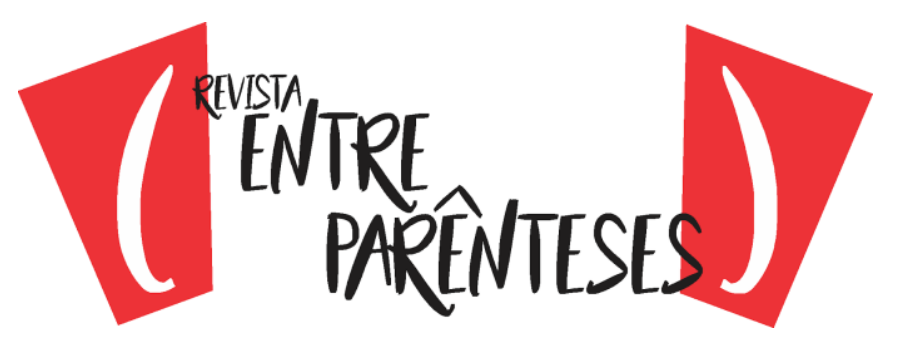

Partindo igualmente de uma perspectiva discursiva, Rojo (2005) revê o pensamento do Círculo de Bakhtin acerca dos gêneros. A autora afirma que as teorias de gênero têm recebido grande atenção no Brasil, especialmente no campo da linguística aplicada ao ensino de línguas. No entanto, a autora defende que os estudos sobre gênero e enunciação deveriam receber um tratamento mais dialógico, "de tal maneira que a noção bakhtiniana de gênero do discurso seja colocada, de uma vez por todas, como um objeto discursivo ou enunciativo" (idem, p. 196), o que está relacionado à importância de se considerar os gêneros como produtores e transformadores das diversas atividades sociais, bem como o discurso como uma arena de lutas e disputas em torno da hegemonia.

Rojo (2004) ainda aponta para a importância da interdiscursividade nas práticas de letramento. A autora afirma que ler na vida, e como uma atividade cidadã, significa colocar o texto em relação com outros textos e discursos que podem ser anteriores a ele, podem estar emaranhados nele ou até mesmo ser posteriores a ele.

Tendo em vista que o foco deste trabalho é o modo de relação dos sujeitos com os discursos que constituem os campos teóricos dos estudos de língua e literatura nos cursos de formação de professores de línguas estrangeiras, podemos destacar que pesquisadores, como Lillis (2003), defendem uma abordagem dialógica para o letramento acadêmico. Para a autora, o trabalho com a construção de sentido na escrita e na leitura nas universidades tem seguido uma estrutura monológica. A reprodução de discursos oficiais do conhecimento permite a hegemonia de práticas pedagógicas monológicas, que adotam um modelo de linguagem como um meio transparente e uma única versão da verdade. Por outro lado, objetivos educacionais dialogicamente orientados visibilizam o jogo entre discursos oficiais e não oficiais, possibilitando, assim, novos modos de produção de sentido no contexto acadêmico, o que implica a existência de múltiplas vozes, múltiplas verdades, múltiplas identidades. No que tange à formação docente, consideramos que a tensão entre os discursos oficiais e não oficiais se dá, por exemplo, na relação entre a cultura popular e os saberes legitimados pelo currículo. 


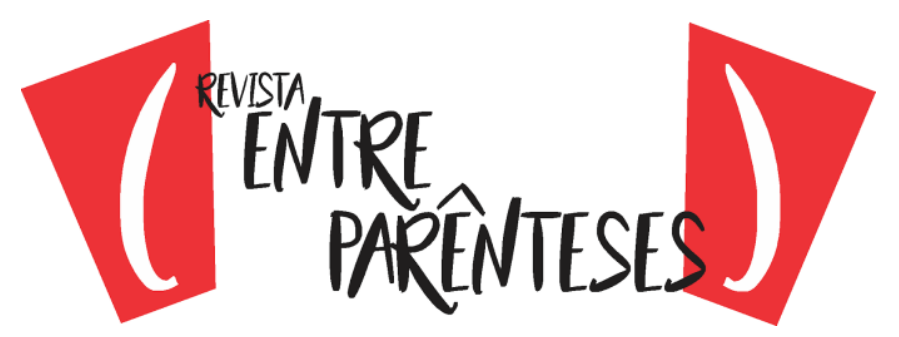

Sendo assim, cabe salientar que a cultura popular não deve ser anulada pela legitimidade dos saberes acadêmicos.

Contudo, consideramos que as diretrizes que orientam os processos formativos fundamentam os mais diversos contextos institucionais, inclusive 0 acadêmico, mantendo uma relação intrínseca com o poder e com a autoridade. Desse modo, a questão central que está em jogo na formação docente é a configuração da licenciatura enquanto espaço que propicia ao licenciando a sua própria constituição como sujeito do discurso. Além disso, tal produção da identidade do professor, entendida como processo de subjetivação, dá-se não apenas pela relação com os discursos humanísticos e pela relação com a prática docente, mas também pela relação com os discursos científicos.

Percebe-se, nesse sentido, a importância de se complexificar as concepções de língua e de sujeito para que se tenha um olhar mais crítico em relação às condições de produção dos diversos discursos e textos que circulam no ambiente universitário. Adotamos, portanto, uma concepção dialógica da linguagem e do discurso, o que implica uma contemplação das disputas discursivas, tensões e lutas entre os participantes da enunciação, abordagem esta que contribui para a compreensão do processo de hegemonização dos significados, uma vez que os discursos que circulam nos contextos em que se dá a formação docente implicam concepções diferentes de sujeito e de linguagem.

\section{RELAÇÃO LÍNGUA/LITERATURA}

$O$ processo de inserção na esfera acadêmica, que constitui o nosso objeto de interesse - além do mais, mediado por uma língua estrangeira -, produz deslocamentos discursivos e subjetivos. Serrani (1997) indica a importância do estudo do desafio subjetivo que a aquisição de uma língua estrangeira representa para o enunciador. Tal desafio se apresenta também na necessidade que os sujeitos têm de articular os diversos domínios discursivos em uma língua estrangeira. Segundo a autora, o sujeito da enunciação deve inscrever-se em discursividades da 


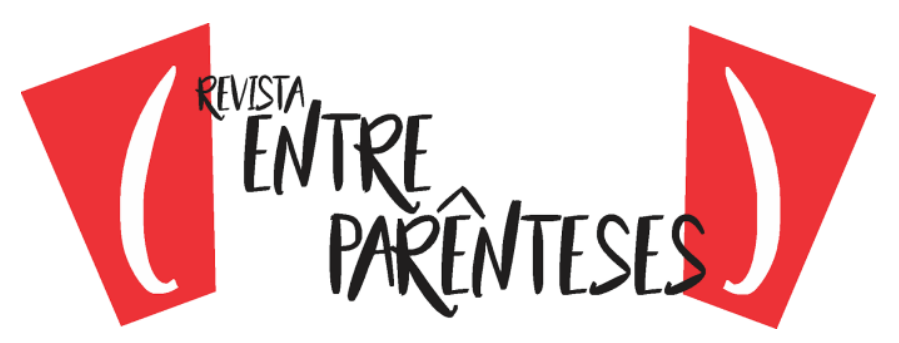

L2, bem como lidar com o estranhamento, principalmente de si mesmo, estabelecido no ensino/aprendizagem formal de uma língua estrangeira, e com as novas possibilidades de atribuição de sentido. Serrani (op. cit.) afirma, portanto, que questões como objetivos de cursos (inclusive de formação de professores), motivações e interesses explícitos dos alunos estão subordinadas às noções de formação discursiva e de interdiscurso.

O conceito de formação discursiva tem, portanto, relevância para a compreensão do processo de produção dos enunciados e dos sentidos. No pensamento foucaultiano, tal conceito relaciona-se às "condições de existência (mas também de coexistência, de manutenção, de modificação e de desaparecimento) em uma dada repartição discursiva" (FOUCAULT, 2014a, p. 47).

Serrani (2000, p. 117) reflete acerca da configuração do aspecto singular do sujeito fragmentado e desejante no contexto atual, em que ainda se sustentam formações ideológicas em relação à ilusão de completude, considerando que o processo de enunciar significativamente em língua estrangeira está "estreitamente ligado a inscrições identificatórias na discursividade da língua alvo".

$\mathrm{Na}$ obra "Discurso e leitura", que discute a respeito da leitura como a condição básica do trabalho intelectual, Orlandi (2012, p. 38) afirma que a Universidade estaria inserida em um circuito no qual se tomaria a leitura em seu caráter técnico imediato, "apenas em termos de estratégias, e de relações pedagógicas marcadas por um exagerado imediatismo", o que corrobora a rigidez das relações acadêmicas.

No que tange especificamente à constituição das faculdades de Letras, Bagno (2012) denuncia o engessamento da formação universitária em relação às mudanças teóricas que se dão nos estudos linguísticos. Segundo o autor, os cursos de Letras são ministrados no Brasil desde o século XIX, originalmente privilegiando a literatura erudita e as línguas clássicas. A formação oferecida pelos institutos e faculdades de Letras na atualidade, entretanto, não condiz com os avanços da linguística moderna, pois não houve uma reestruturação efetiva dos cursos.

O trabalho com as literaturas nos cursos de Letras, por sua vez, parece, 


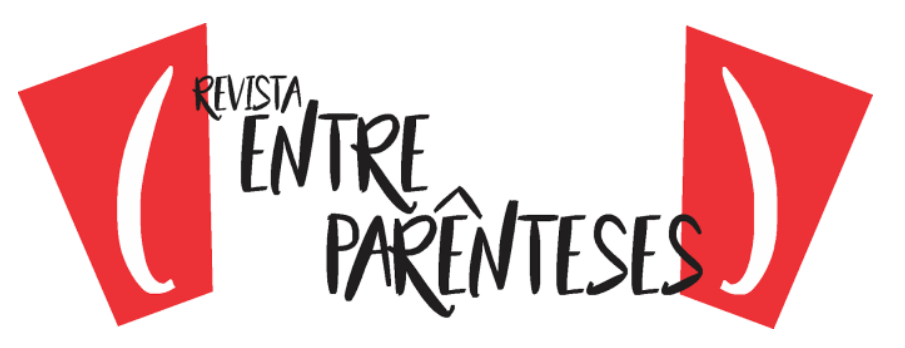

de maneira semelhante, não ser realizado de modo significativo. Costa et al. (2011), a partir da análise de ementas de disciplinas de teoria literária e literaturas brasileira e portuguesa de uma universidade estadual situada no Norte do Brasil, verificam, por exemplo, um tradicionalismo da periodização literária ao longo de toda a grade curricular, o que indiciaria a falta de reconhecimento da relação entre literatura e cultura.

Tais questões se ligam, de certo modo, à maneira como se dá a formação intelectual dos futuros docentes de línguas estrangeiras. Nesse sentido, Marcuschi (2004), a partir da análise de textos produzidos por pós-graduandos da área de Letras, aponta para a legitimação atribuída por esses sujeitos aos conteúdos, que nem sempre dialogam com as reais demandas do professor de línguas, em detrimento da reflexão crítica. $O$ autor defende, em contrapartida, uma formação que gere modelos de análise e interpretação crítica, isto é, pautada na "autonomia para a busca de caminhos e na percepção do que é relevante" (idem, p. 15) ao invés de propiciar a mera apropriação de conteúdos.

No que concerne ao contexto europeu, de cujo modelo a formação em Letras no Brasil é herdeira, Bourdieu (2011a) situa a faculdade de Letras ao mesmo tempo no campo científico e no campo intelectual. O sociólogo a caracteriza como o lugar de poderes propriamente sociais que participam das estruturas mais fundamentais da ordem social, situando-a tanto no campo científico quanto no campo intelectual em razão de, por um lado, ela ser o lugar de poderes que participam das estruturas mais essenciais da ordem social e, por outro, ter a notoriedade intelectual como a única espécie de capital que verdadeiramente the pertence.

De acordo com Bourdieu (2011b, p. 3), "um campo é um microcosmo autônomo no interior de um macrocosmo social". Um campo, portanto, é autônomo por ter sua própria lei e por ter em si mesmo a regra e o princípio de seu funcionamento, pressupondo uma competência específica, bem como uma espécie particular de capital.

É importante, a partir de tais considerações, explicitar os desdobramentos 


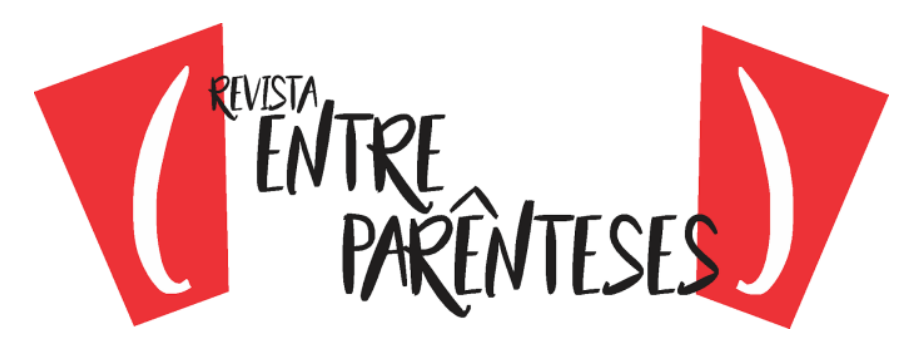

que os conceitos de campo científico e de campo intelectual possuem no pensamento de Bourdieu, para quem o campo intelectual

constituye un sistema de líneas de fuerza: esto es, los agentes o sistemas de agentes que forman parte de él pueden describirse como fuerzas que, al surgir se oponen y se agregan, confiriéndole su estructura específica en un momento dado del tiempo ${ }^{2}$ (BOURDIEU, 2002, p. 9).

O autor defende que o movimento romântico do século XIX, decorrente da industrialização das sociedades europeias, propiciou o fortalecimento de um mercado artístico, cuja produção específica passou a ser submetida às mesmas condições que a produção em geral.

Em relação ao campo científico, Bourdieu (1976) o define como o lugar de uma

luta competitiva que tem por desafio específico o monopólio da autoridade científica, inseparavelmente definida como capacidade técnica e como poder social, ou se se preferir, o monopólio da competência científica, entendida no sentido de falar e intervir legitimamente (ou seja, de maneira autorizada e com autoridade) em matéria de ciência, que é socialmente atribuída a um agente determinado (BOURDIEU, op. cit., p. 89. Tradução livre).

Caracterizar o campo científico como um lugar de lutas, portanto, implica a ruptura da imagem pacífica de "comunidade científica". Além disso, o sociólogo defende que cada um dos agentes se compromete com a imposição do valor de seus produtos e da sua própria autoridade enquanto um produtor legitimado, o que leva ao desafio de se impor a definição de ciência.

A tensão que se verifica no contexto da formação de docentes de línguas estrangeiras não se dá apenas entre os campos linguístico e literário. Em relação à linguística, que adquiriu status científico com a publicação do "Curso de linguística geral” de Saussure (cf. MARTELOTTA et al., 2008, p. 22), Bourdieu (2011a, p. 163) afirma que "as tomadas de posição em matéria de teoria, de método, de técnica e

\footnotetext{
2 "Constitui um sistema de linhas de força: isto é, os agentes ou sistemas de agentes que fazem parte dele podem ser descritos como forças que, ao surgir, se opõem e se acrescentam, conferindo-lhe sua estrutura específica em um momento dado no tempo." (Tradução livre)
} 


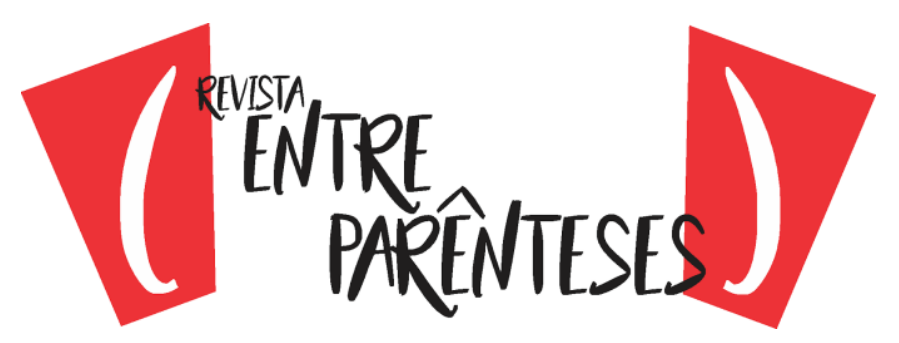

até mesmo de estilo são sempre estratégias sociais em que os poderes se afirmam e são reivindicados". As linhas da linguística, portanto, divergem entre si por deterem técnicas e métodos específicos, que, por sua vez, encetam diferentes concepções de língua. $O$ estruturalismo norte-americano, vigente na primeira década do século $\mathrm{XX}$, por exemplo, restringia-se "à classificação dos segmentos que aparecem nos enunciados do corpus e à identificação das leis de combinação de tais segmentos" (MARTELOTTA et al., op. cit., p. 125). Já a linguística gerativa

propõe-se a analisar a linguagem humana de uma forma matemática e abstrata (formal), que se afasta bastante do trabalho empírico da gramática tradicional, da linguística estrutural e da sociolinguística, e se aproxima da linha interdisciplinar de estudos da mente humana conhecida como ciências cognitivas (idem, p. 130).

Por outro lado, no campo literário, ao invés de disputas discursivas entre as diversas linhas teóricas, percebe-se um maior apagamento nas fronteiras entre as diferentes perspectivas teórico-críticas, o que Eagleton (2006, p. 299) constata ao afirmar que "os críticos que se ufanam de seu pluralismo geralmente podem fazê-lo porque os diferentes métodos que usam não são, afinal, tão diferentes assim".

No que diz respeito à relação histórica entre estudos literários e linguísticos, Maingueneau (2012, p. 16) afirma que a filologia, cujo corpus de referência era/é constituído por textos literários, foi perdendo espaço em detrimento da autonomização crescente da linguística, que não considerava os textos de literatura como mostras autênticas da língua e, portanto, "tendia a isolar as obras literárias do resto da produção verbal", privilegiando os intercâmbios verbais cotidianos ao se constituir como uma disciplina científica.

A respeito da questão apontada acima, Bourdieu (2011a) considera, de modo semelhante, que a irrupção da linguística nos domínios acadêmicos teve como consequência a desvalorização das disciplinas literárias.

Em relação ao contexto brasileiro, Brait (2000) afirma que a tendência maior aos estudos das línguas ou a disciplinas voltadas para o estudo da língua tem a ver com as mudanças na visão acerca desses estudos introduzidas no Brasil a 


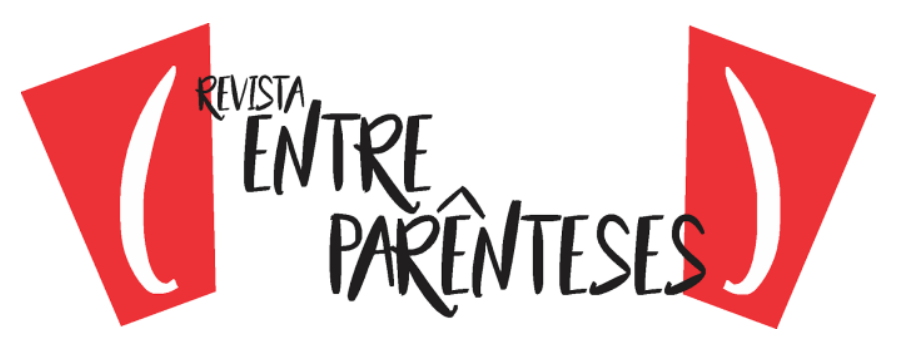

partir da segunda metade do século XIX pelos estudos comparativos, inaugurandose, assim, o período científico da filologia. Tal tendência, de acordo com a autora, liga-se a paradigmas cientificistas que vigoram, tanto nas ciências gerais quanto nas ditas humanidades, entre o final do século XIX e o começo do XX.

De acordo com Fiorin (2008), até por volta da década de 60 do século XX, os estudos linguísticos e literários não mantinham relações entre si, já que não se considerava necessário recorrer a qualquer categoria linguística para a análise do texto literário. O estruturalismo dos anos 60, porém, propiciou uma aproximação entre a literatura e as aquisições da linguística e, mais especificamente, da semiologia para o desenvolvimento de uma teoria do texto literário. Entre o final da década de 70 e o início dos anos 80, a linguística e a literatura novamente rompem laços: os estudiosos de literatura, de um lado, voltam a utilizar a gramática tradicional para justificar algum fato da língua que servisse de apoio a suas conclusões; os linguistas, por sua vez, abandonam a perspectiva semiológica e voltam-se para os fatos de língua. Fiorin (op. cit.) defende ainda a necessidade de que os conceitos linguísticos sejam um instrumento de investigação do texto literário, que, a partir de uma concepção discursiva, seria estudado como processo enunciativo e totalidade textual. $O$ autor defende, além disso, que, a partir dos estudos literários, se pense "a natureza da linguagem humana como um mecanismo que contém as regras de sua própria subversão" (idem, ibid, p. 50), a fim de se ampliar a compreensão da linguagem e dos recursos linguísticos. Nesse sentido, as teorias do discurso são importantes na medida em que concebem toda e qualquer manifestação da linguagem como uma prática discursiva e, portanto, questionam a dicotomização que tradicionalmente se faz entre língua e literatura.

A partir dessa trajetória da relação entre os estudos linguísticos e literários, podemos afirmar que os cursos de Letras e, consequentemente, a formação dos professores de línguas são historicamente constituídos por lutas discursivas entre os distintos saberes que constituem as licenciaturas. Isso significa que os campos epistemológicos ligados à língua e à literatura que compõem os currículos das faculdades de Letras estão em constante tensão para ocupar um 


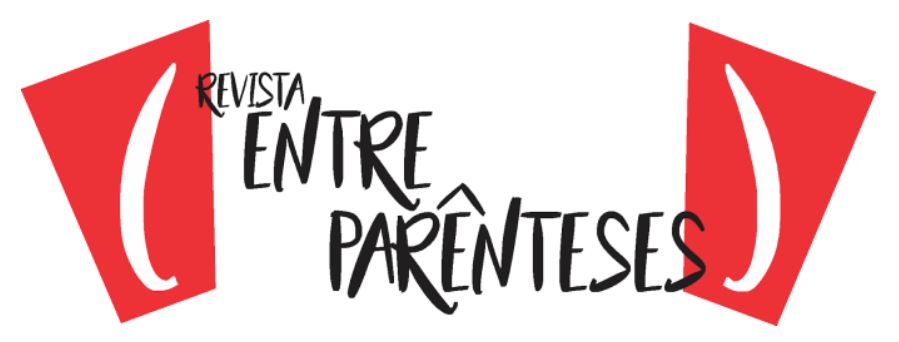

lugar de poder nos âmbitos da formação docente.

Para explicitar a noção de formação literária referida neste artigo, é preciso, antes, definir a concepção de literatura aqui adotada. Eagleton (2006, p. 13) considera que se pode "pensar na literatura menos como uma qualidade inerente, ou como um conjunto de qualidades evidenciadas por certos tipos de escritos (...) do que como as várias maneiras pelas quais as pessoas se relacionam com a escrita".

Para o autor, os julgamentos de valor contribuem muito para se decidir o que é e o que não é considerado como literatura, fato que se relaciona aos interesses dos diversos grupos sociais. Sendo assim, julga-se um discurso como literário ou como não literário não pela "natureza" ou pelas características "intrínsecas" a esse discurso, e sim pelos juízos de valor e pelas ideologias que estão em jogo para que se realize essa decisão. Desse modo, o autor lança mão dos seguintes argumentos para defender a ideia de que não há uma linguagem que seja intrinsecamente literária: a) pode-se pensar que o discurso literário torna estranha a fala comum, mas deve-se levar em consideração o pressuposto de que não existe uma linguagem "normal" que seria usada por todos os membros de uma sociedade; b) apesar de o texto de literatura ser constituído por figuras de linguagem, não há nenhum artifício "literário" que não seja empregado com frequência no discurso cotidiano; e c) pode-se considerar que o discurso corrente é pragmático, diferentemente da literatura, mas na verdade não é possível fazer uma distinção nítida entre as maneiras "práticas" e "não práticas" de nos relacionarmos com as diversas linguagens.

Podemos corroborar a discussão levantada por Eagleton a partir das considerações de Maingueneau (2012, p. 8), que afirma que a constituição do "objeto literário" sofre variações "de acordo com o estatuto dos agentes, bem como dos lugares que estes ocupam na produção e na circulação dos discursos".

A disputa que se dá entre os grupos sociais pela decisão do que constitui a literatura aproxima-se ao conceito foucaultiano de poder-saber. Segundo Foucault (2013, p. 30), poder e saber são duas instâncias que estão diretamente ligadas, pois "não há relação de poder sem constituição correlata de um campo de saber, nem 


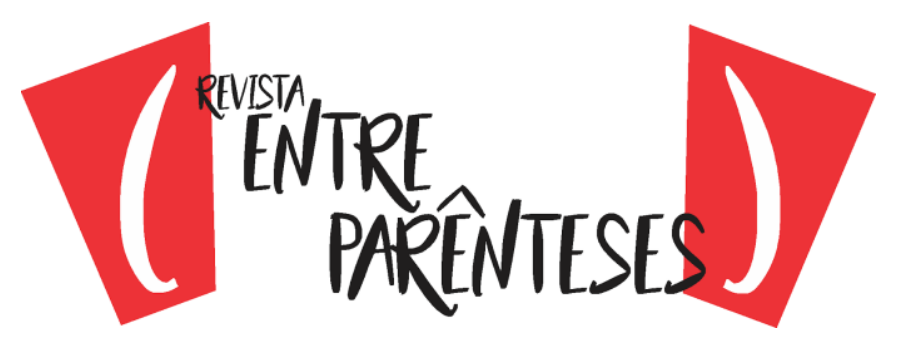

saber que não suponha e não constitua ao mesmo tempo relações de poder".

É importante ressaltar que, para Foucault (2014b, p. 101), as relações de poder são também produtivas, uma vez que ele não as entende como um sistema de dominação que um grupo exerce sobre outro, mas sim como "o suporte móvel das correlações de força". Segundo o filósofo, o poder é produzido a cada instante e "se exerce a partir de inúmeros pontos e em meio a relações desiguais e móveis" (idem, p. 102) ao invés de ser considerado como uma potência que alguns grupos detêm. O princípio das relações de poder, portanto, não implica uma oposição binária entre dominadores e dominados e, embora existam pontos de resistência, estes representam não só o papel de adversário, mas também de apoio, estando distribuídos de modo irregular.

Foucault (2012, p. 17) ainda afirma que a vontade de saber apoia-se sobre um suporte e uma distribuição institucional e é reconduzida "pelo modo como o saber é aplicado em uma sociedade, como é valorizado, distribuído, repartido e de certo modo atribuído", além de exercer sobre os outros discursos uma espécie de pressão e um poder de coerção. Dessa maneira, vemos que os discursos relacionados aos diversos campos epistemológicos que embasam a formação docente têm um poder coercitivo uns em relação aos outros, tendo em vista que a questão da valorização de um certo conhecimento é essencial no processo de interação de determinados posicionamentos discursivos. Tal relação de poder entre os discursos, no entanto, é também produtiva na medida em que propicia o desenvolvimento de diferentes disciplinas e áreas do saber.

Considerar tais questões, no entanto, não significa desconsiderar o valor da literatura na sociedade. Para Cosson (2014, p. 16), por exemplo, "é no exercício da leitura e da escrita dos textos literários que se desvela a arbitrariedade das regras impostas pelos discursos padronizados da sociedade letrada". Não obstante, é notório que o valor atribuído à literatura vem sendo cada vez mais questionado. Nesse sentido, Zilberman (1991) afirma que a prática do ensino de literatura em sala de aula reage a transformações ocorridas no Brasil, tais como a necessidade de escolarizar a população com rapidez, como maneira de acelerar a modernização da 


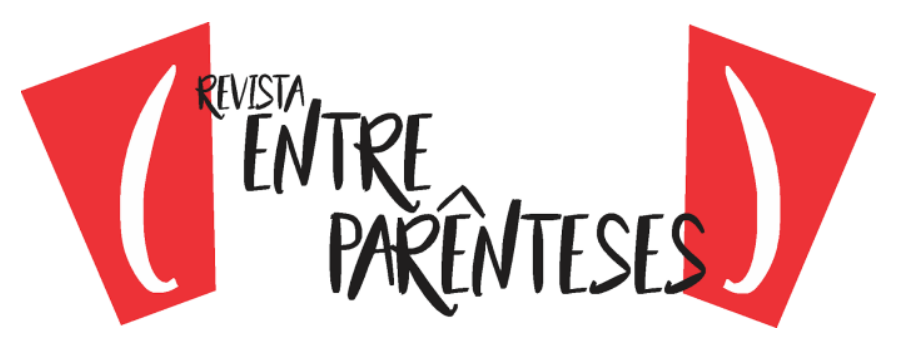

sociedade.

A disputa pela hegemonização de um determinado campo epistemológico, que se manifesta tanto na organização curricular em vigor quanto nos próprios discursos que circulam no contexto acadêmico, corrobora igualmente a dicotomização que tradicionalmente se faz entre língua e literatura. No que concerne à questão da formação docente, o âmbito dos cursos de licenciatura desvela igualmente essas tensões, na medida em que os saberes linguísticos e literários se vinculam a formações discursivas distintas, mantendo entre si relações de conflito e disputa.

O distanciamento entre a linguística e a literatura é também discutido por Fiorin (2008), que denuncia a separação entre os estudos linguísticos e literários e apresenta uma visão pessimista em relação à possibilidade de uma renovação do diálogo entre a linguística e a literatura. Consideramos, no entanto, que é preciso compreender os discursos que perpetuam tal cisão no âmbito da formação de professores de línguas a fim de promover um agenciamento que propicie nos meios acadêmicos uma interação maior entre os campos do conhecimento referentes aos estudos linguísticos e literários.

Fiorin (2008, p. 39) denuncia ainda os possíveis danos da especialização não apenas no âmbito das Letras, mas em qualquer área, tendo em vista que a disciplinarização acarreta uma institucionalização nociva a todo e qualquer fazer científico; o autor defende, portanto, que a interdisciplinaridade "é uma das formas mais interessantes e produtivas de trabalho científico de nossa época" por supor a interseção, a sobreposição e a reorganização de disciplinas, que podem buscar elementos em outras áreas e ciências.

As críticas de Fiorin se relacionam à reflexão de Foucault (2012, p. 34) a respeito da noção de disciplina, que, para o filósofo, constitui "um princípio de controle da produção do discurso", um princípio de coerção dotado de uma função restritiva.

A noção de disciplina, em Foucault, ganha a acepção dúplice de norma e de campo epistemológico, evidenciando-se como mecanismo de controle dos corpos 


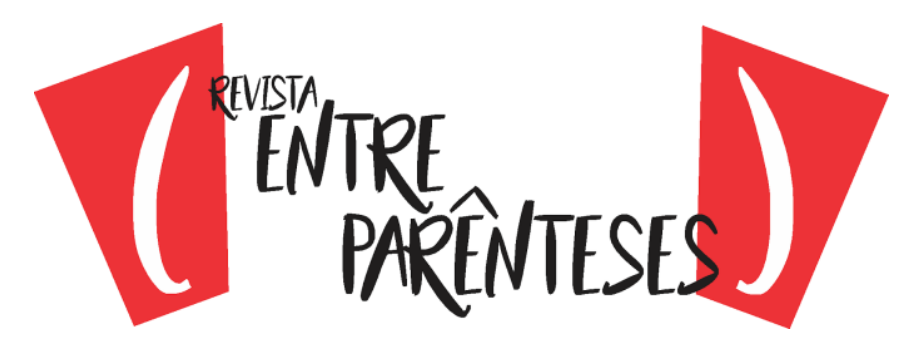

e do conhecimento. Ambas as concepções que o termo "disciplina" adquire estão relacionadas às tecnologias de controle e ao conceito de biopoder (FOUCAULT, 2014b). Segundo o filósofo, os diferentes modos de disciplina - enquanto técnicas de controle -, tais como o sistema escolar, tiveram rápido desenvolvimento na era moderna, período de explosão de mecanismos diversos que tinham como função a sujeição e o controle dos corpos das populações. O biopoder, portanto, é um processo político de controle da vida através da disciplina, das normas e das instituições, tornando os corpos produtivos e distribuindo-os em um domínio de valor e utilidade. Sendo assim, Foucault (op. cit., p. 153-154) afirma que "os processos da vida são levados em conta por procedimentos de poder e de saber que tentam controlá-los e modificá-los" e que a relação poder-saber é um agente de transformação da vida.

Também é importante considerar as reflexões de Foucault (2014a) em relação ao conceito de arquivo. Segundo o autor, o arquivo "faz aparecerem as regras de uma prática que permite aos enunciados subsistirem e, ao mesmo tempo, se modificarem regularmente" (idem, ibid, p. 159). O arquivo, portanto, é o sistema da formação e da transformação dos enunciados e também o próprio conjunto de enunciados a partir dos quais não se tenta estabelecer uma cronologia nem uma continuidade, mas sim uma regra de formação que tende à dispersão, ao autoocultamento, mascarando, assim, as relações de poder.

De acordo com Coracini (2007, p. 16), é o arquivo que "faz com que os discursos se modifiquem, que alguns dizeres, longínquos no tempo, permaneçam e outros, mais recentes, se esfumem e até desapareçam". A partir de tal afirmação podemos compreender que as disputas discursivas que se dão não apenas entre os diversos campos epistemológicos, mas também entre os diferentes posicionamentos assumidos dentro de uma mesma área do saber, seguem a lógica do arquivo, que é "a lei do que pode ser dito, o sistema que rege o aparecimento dos enunciados como acontecimentos singulares" (FOUCAULT, 2014a, p. 158).

Os discursos que são produzidos a partir das relações interpessoais entre licenciandos e professores (universitários e da Educação Básica), portanto, deixam 


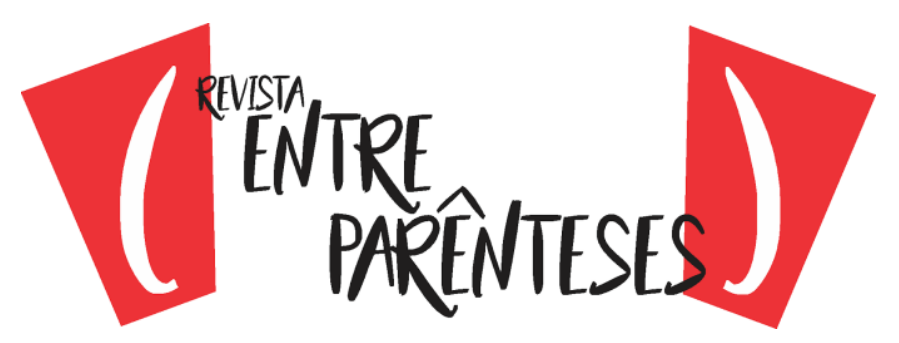

rastros no (in)consciente dos sujeitos, que, mesmo sem saber, incorporam fragmentos que farão parte de sua constituição subjetiva. Desse modo, refletir acerca da relação entre arquivo e processos de subjetivação pode ser produtivo na medida em que nos dá aportes para a compreensão das diferentes práticas dos sujeitos envolvidos nos processos de formação docente.

Tendo em vista a importância de propiciar o diálogo entre os campos epistemológicos ligados aos estudos linguísticos e literários, recuperamos a proposta de Serrani (2014) de articulação entre língua e cultura que, no âmbito da formação docente, são possibilitadas pelo componente entendido como língua-discurso. Para fazer tal aproximação, a autora delimita parâmetros multidimensional-discursivos 3 relativos à interculturalidade, à língua-discurso e às práticas verbais, componentes que se relacionam de maneira interdependente na progressão de conteúdos e atividades, abordando, assim, as noções pilares da concepção discursiva da linguagem: o intradiscurso - que se dá a partir da relação de um determinado discurso com outros discursos -, o interdiscurso - relativo a memórias sóciohistóricas constitutivas de todo sujeito e ao espaço discursivo.

Em seu artigo, Serrani demonstra que em um texto pertencente ao gênero poético, como "Ni colorín ni colorado", de Mario Benedetti, poema analisado pela autora, podem ressoar gêneros não somente literários, como os de narração de contos infantis, mas também gêneros não literários, como o jornalístico e o institucional-burocrático. Isso se deve à heterogeneidade discursiva dos textos e gêneros, que precisa ser considerada no "trabajo de formación sobre diversidad enunciativa en clases de lengua y cultura" ${ }^{4}$ (SERRANI, op. cit., p. 25), de modo a problematizar a dicotomização que se faz entre língua e literatura.

Os conceitos aqui abordados, portanto, nos possibilitam refletir acerca dos movimentos de cisão e de diálogo entre os campos epistemológicos referentes aos

\footnotetext{
${ }^{3}$ De acordo com Serrani (2014, p. 19, tradução livre), no planejamento multidimensional-discursivo "a progressão de conteúdos e atividades não ocorre exclusivamente a partir da dimensão linguística, seja na perspectiva que for (tradicional, estruturalista, nocional-funcional, comunicativista, sóciointeracionista, semântico-discursiva, etc.", mas sim de forma interdependente entre os componentes intercultural, de língua-discurso e de práticas verbais.

4 "Trabalho de formação sobre diversidade enunciativa em aulas de língua e cultura." (Tradução livre)
} 


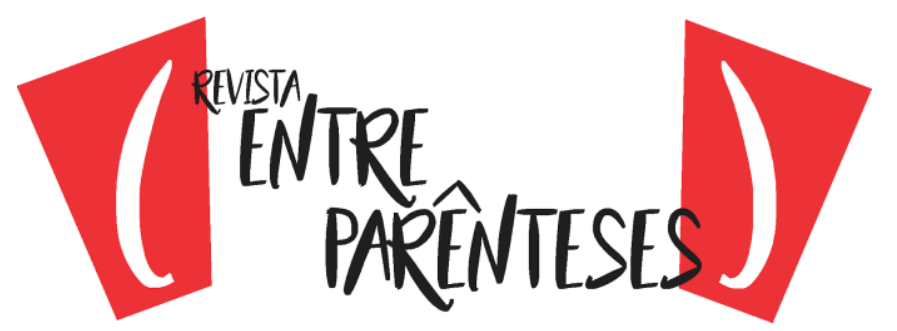

estudos linguísticos e aos estudos literários, de modo a que se problematize a relação entre as diferentes formações discursivas que atravessam os discursos que circulam nos contextos em que se dão as licenciaturas em línguas estrangeiras.

Ademais, as reflexões feitas a respeito da concepção dialógica e heterogênea de sujeito e de linguagem e do histórico da cisão entre os saberes linguísticos e literários configuram um referencial teórico relevante para a compreensão e problematização dos discursos que perpetuam as disputas discursivas entre língua e literatura no âmbito da formação de docentes de língua estrangeira. As questões levantadas neste artigo, portanto, nos dão embasamento para discutir e analisar os espaços em que se dá a formação de professores enquanto contextos atravessados por diferentes formações discursivas, que mantêm entre si relações não apenas de tensão, mas também de imbricação, constituindo, assim, movimentos simultâneos de diálogo e de reprodução da dicotomia entre língua e literatura. 


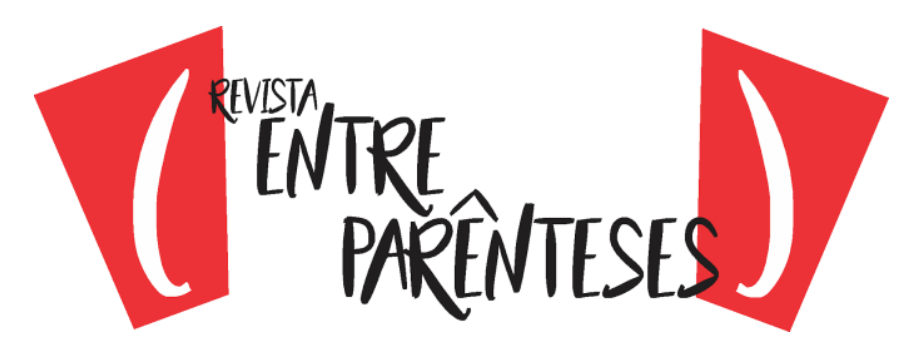

\section{Referências}

AUTHIER-REVUZ, J. Entre a transparência e a opacidade: um estudo enunciativo do sentido. Porto Alegre: EDIPUCRS, 2004.

BAGNO, M. Curso de Letras? Pra quê?. In: ENCONTRO BRASILIENSE DE ESTUDANTES DE LETRAS, 7., 2012, Brasília. Conferência de abertura proferida em 22 nov. 2012.2 Disponível em: <http://linguagemdocencia.blogspot.com.br/2012/11/curso-de-letras-pra-queconferencia-de.html>. Acesso em 13 out. 2014.

BAKHTIN, M. Estudo das ideologias e filosofia da linguagem. In: Marxismo e filosofia da linguagem. São Paulo: Hucitec, 2006.

BOURDIEU, P. Campo de poder, campo intelectual. Buenos Aires: Editorial Montressor; Jungla Simbólica, 2002.

Homo academicus. Florianópolis: Ed. da UFSC, 2011a.

Le champ scientifique. Actes de la recherche en sciences sociales, Paris, n. 1-2, 1976.

O campo político. Revista Brasileira de Ciência Política, Brasília, n. 5, jan./jul. 2011b, p. 193-216. Disponível em: <http://www.scielo.br/pdf/rbcpol/n5/a08n5.pdf>. Acesso em: 07 ago 2015.

BRAIT, B. Língua e literatura: uma falsa dicotomia. Revista ANPOLL, Florianópolis, n. $8, \quad$ p. 187-206, jan./jun. 2000. Disponível em: <http://anpoll.org.br/revista/index.php/revista/article/view/355/364>. Acesso em: 30 dez. 2014.

CORACINI, M. J. Sujeito, identidade e arquivo: entre a impossibilidade e a necessidade de dizer(-se). In: . A celebração do outro: arquivo, memória e identidade. Campinas: Mercado de Letras, 2007.

Cosson, R. A literatura e o mundo. In: Letramento literário: teoria e prática. São Paulo: Contexto, 2014.

COSTA, M. et al. Letramento literário e formação do professor: o ensino de literatura no meio universitário. Revista Entreletras, Araguaína, n. 3, 2ํㅗ․ $\mathrm{sem}$ 2011. Disponível em:

<http://www.uft.edu.br/pgletras/revista/capitulos/4._letramento_literario_e_formacao_ do_professor_larissa.pdf>. Acesso em: 22 dez. 2014.

EAGLETON, T. Teoria da literatura: uma introdução. São Paulo: Martins Fontes, 


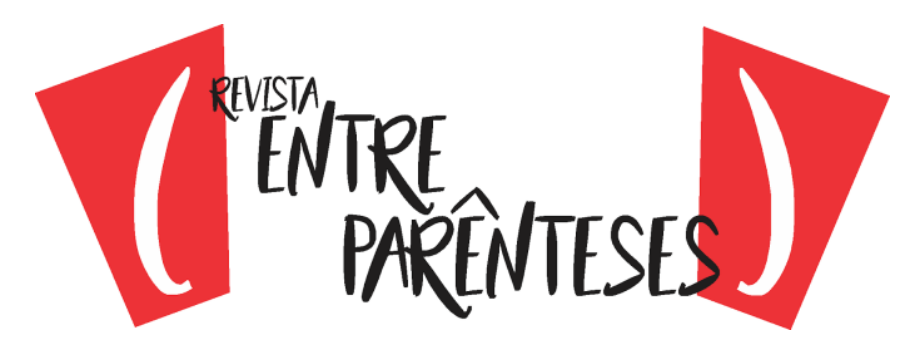

2006.

FIORIN, J. L. Linguagem e interdisciplinaridade. Alea, Rio de Janeiro v. 10, n. 1, jan./jun., 2008, p. 29-53. Disponível em: <http://www.scielo.br/pdf/alea/v10n1/v10n1a03.pdf>. Acesso em: 03 jan. 2015.

FOUCAULT, M. A arqueologia do saber. Rio de Janeiro: Forense Universitária, 2014a.

A ordem do discurso. São Paulo: Loyola, 2012.

2014b.

História da sexualidade: a vontade de saber. 1. São Paulo: Paz e Terra,

Vigiar e punir. Petrópolis: Vozes, 2013.

LILLIS, T. Student writing as "academic literacies": drawing on Bakhtin to move from critique to design. Language and education, United Kingdon v. 17, n. 3, p. 192-207, 2003.

MAINGUENEAU, D. Análise de textos de comunicação. São Paulo: Cortez, 2013.

. Discurso literário. São Paulo: Contexto, 2012.

MARCUSCHI, L. A. A formação intelectual do estudante de Letras. In: ENCONTRO NACIONAL DE ESTUDANTES DE LETRAS, 25., 2004, Florianópolis. Anais... Florianópolis: UFSC, 2004.

MARTELOTTA, M. (Org.). Manual de linguística. São Paulo: Contexto, 2008.

ORLANDI, E. Discurso e leitura. São Paulo: Cortez, 2012.

ROJO, R. Gêneros do discurso e gêneros textuais: questões teóricas e aplicadas. In: MEURER, J. L. et al. (Org). Gêneros: teoria, métodos, debates. São Paulo: Parábola, 2005.

Letramento e capacidades de leitura para a cidadania. São Paulo: SEE; CENP, 2004.

SERRANI, S. La noción de cultura, la lengua y los Estudios Hispánicos: enfoque discursivo-cultural de un poema de Benedetti. Intersecciones, São Paulo, n. 2, $1^{\circ}$ sem./2014. Disponível em: <http://www.apeesp.com.br/wpcontent/uploads/03_CONF_SILVANA.pdf>. Acesso em: 18 out. 2014.

. Singularidade discursiva na enunciação em segundas línguas. Cadernos 


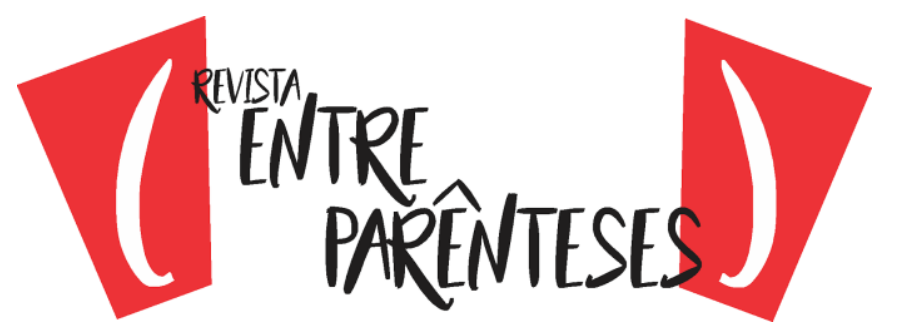

de Estudos Linguísticos, Campinas, v. 38, p. 109-120, jan./jun. 2000. Disponível em: <http://revistas.iel.unicamp.br/index.php/cel/article/view/2684/4315>. Acesso em: 29 ago. 2013.

FELTA, Formações discursivas e processos identificatórios na aquisição de línguas.
São Paulo, v. 13 n. 1, fev. 1997. Disponível em: <http://www.leffa.pro.br/textos/Serrani_Infante.pdf>. Acesso em: 30 ago. 2013.

ZILBERMAN, R. A leitura e o ensino da literatura. São Paulo: Contexto, 1991.

Recebido em: 20/04/2020

Aceito em: $16 / 05 / 2020$ 